К. В. Базіло, к.т.н., доиент,

С. О. Білокінь, к.m.н.,

М. О. Бондаренко, к.т.н., доцент,

В. В. Медяник

Черкаський державний технологічний університет

б-р Шевченка, 460, м. Черкаси, 18006, Україна

\title{
ДОСЛІДЖЕННЯ МІКРОЕЛЕКТРОМЕХАНІЧНИХ П'ЄЗОЕЛЕКТРИЧНИХ СТРУКТУР МЕТОДОМ АТОМНО-СИЛОВОЇ МІКРОСКОПІї
}

Нині провідні виробники радіоелектронних компонентів серійно випускають досить великий перелік елементів, до складу яких включені різні мікроелектромеханічні структури. Основна перевага використання у вимірювальних приладах елементів з п'єзокерамічних матеріалів обумовлюсться їх особливою структурою, яка дозволяє реалізувати в одному такому елементі принципово різні схеми, наприклад, для одночасного вимірювання температури, тиску $i$ вологості. Метою роботи є вивчення методом атомно-силової мікроскопії прихованих мікродефектів і мікронерівностей поверхонь п'єзоелектричних перетворювачів.

Ключові слова: мікроелектромеханічні структури, атомно-силова мікроскопія, мікронерівність поверхні, мікродефекти.

Вступ. Нині провідні виробники радіоелектронних компонентів серійно випускають досить великий перелік елементів, до складу яких включені різні мікроелектромеханічні структури (МЕМС), наприклад, різні акселерометри, які випускаються багатомільйонними тиражами, резонатори і реалізовані на їх основі фільтри електричних сигналів, трансформатори та інші мікромініатюрні електромеханічні системи [1].

П'єзоелектричні перетворювачі різноманітних форм, розмірів і функціонального призначення використовуються в контрольновимірювальних приладах, мікротехніці і медичних приладах. Однак подальше вдосконалення таких перетворювачів шляхом їх мініатюризації неможливе без прогнозування терміну їх безвідмовної експлуатації. Особливо важливо це врахувати при використанні п'єзоелектричних перетворювачів в ультразвукових хірургічних інструментах, де вихід 3 ладу таких перетворювачів може призвести до неправильної роботи пристрою, а в окремих випадках - до небезпеки для здоров'я людини [2].

Основними показниками, які впливають на безперебійну роботу і надійність експлуатації п'єзоелектричних перетворювачів, $\epsilon$ мікронерівності поверхонь п'єзоелектричних елементів і відсутність на них мікродефектів.

Тому метюю роботи $є$ проведення досліджень і аналізу мікрогеометрії поверхонь п'єзоелектричних перетворювачів методом атомно-силової мікроскопії для визначення прихованих мікродефектів і мікронерівностей поверхонь цих перетворювачів.

Методи та матеріали. Відмінною рисою між MEMC і звичайними п'єзоелементами $\epsilon$ спосіб електродування робочих поверхонь. Звичайні п'єзоелектричні елементи мають, як правило, суцільне електродування поверхні. У деяких спеціальних випадках електроди поділяються (розрізаються) на окремі області, які не мають між собою гальванічного зв'язку. У $\mathrm{MEMC,} \mathrm{як} \mathrm{правило,} \mathrm{використовується} \mathrm{часткове}$ електродування робочих поверхонь, коли тільки частина поверхні поляризованого сегнетоелектрика покривається металевою плівкою. Цей спосіб електродування дозволяє збуджувати в об'ємі МЕМС кілька типів пружних коливань. Маніпулюючи геометричними параметрами електродування поверхонь, можна управляти енергетикою коливальних процесів в MEMC, тобто створювати умови, коли один тип коливання буде домінувати над іншими за амплітудою вектора пружних зміщень матеріальних частинок.

Якщо часткове електродування виконано 3 порушенням осьової симетрії всієї конструкції, то відкриваються додаткові можливості по управлінню параметрами напруженодеформованого стану п'єзоелектричного диска і передавальними характеристиками електромеханічної системи в цілому. 
Сучасні технології дозволяють створювати мікроструктури, які об'єднують у собі властивості та якості електронних схем і механічних коливальних систем. В одному корпусі (чіпі) можуть знаходитися десятки однотипних модулів. Під модулем розуміється сукупність мікромініатюрної механічної коливальної системи і електронної схеми, що забезпечує іiі роботу. Послідовне з'єднання декількох модулів 3 досить простими індивідуальними характеристиками дозволяє створювати пристрої з унікальними параметрами. Сказане можна проілюструвати наступним прикладом (рис. 1) [3].

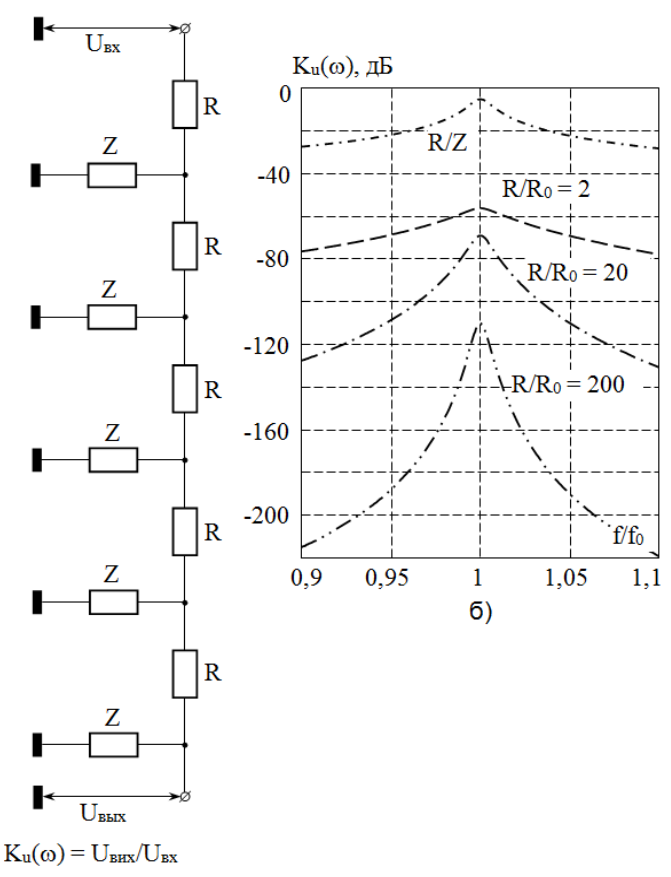

a)

Рис. 1. Сходова схема включення (а) однакових дільників напруги і частотні характеристики сходового фільтра (б)

Припустимо, що $є$ найпростіший дільник електричної напруги, в верхнє плече якого включений резистор $R$, а в нижнє MEMC-резонатор, електричний імпеданс котрого $Z_{e l}(\omega)$ визначається характеристичним опором $R_{0}=5$ Ом та добротністю $Q_{0}=100$. Якщо прийняти значення $R=1000$ Ом, то коефіцієнт ділення одиночного дільника змінюється так, як це показано на рис. 1, б штрихпунктирною кривою, виділеною символом $R / Z$. По осі абсцис на рис. 1, б відкладається безрозмірна частота $f / f_{0}$. Чітко видно, що одиночний дільник забезпечує пригамовуван- ня сигналу поза смугою пропускання не більше ніж на 30 дБ. Послідовне з'єднання за сходовою схемою (рис. 1, а) лише п'яти подібних дільників забезпечує пригамовування сигналу поза смугою пропускання не менше 120 дБ. Криві, відмічені на рис. 1, 6 символами $R / R_{0}=2$ i $R / R_{0}=20$, показують, що при фіксованих параметрах MEMC-резонатора результат роботи сходової схеми значною мірою залежить від вибору величини резистора $R$. Згасання сигналу на резонансній частоті можна компенсувати за допомогою коригувальних підсилювачів, які включаються між ланками сходової схеми [3].

Розглянутий приклад переконливо демонструє можливості створення за допомогою мікросистемних технологій у малих об'ємах (в об'ємі одного корпусу мікросхеми) пристроїв з унікальними характеристиками і параметрами.

Аналізуючи конструкції сучасних дискових п'єзоелементів [4-7], можна помітити, що більшість із них мають несиметричне розташування електродів на своїй поверхні (наприклад, рис. 2 [4]). Таке розташування електродів, а також кріплення елементів викликає наявність невісесиметричних коливань у дискових елементах. При аналізі частотних характеристик таких пристроїв необхідно враховувати вплив на них цих коливань.

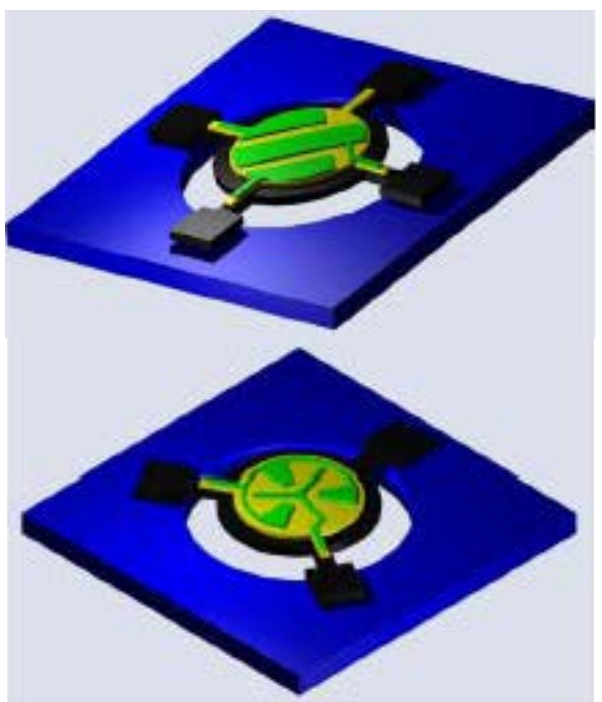

Рис. 2. Модель сучасних дискових МЕМС-резонаторів

У роботах $[8,9]$ було показано, що термічним осадженням у вакуумі можна отримати впорядковані наноструктури на поверхнях п'єзокерамічних елементів. 
Серед існуючих неруйнівних методів контролю, за допомогою яких можна визначити як стан поверхні п'єзоелектричних елементів (ії мікрогеометрію та пористість), так і розміри сформованих у ній структур, найбільш перспективним є метод атомно-силової мікроскопії, що має високу точність (до 1 нм), чутливість (близько $10^{-12} \mathrm{H}$ ) та продуктивність.

Експериментальні дослідження полягали у формуванні тонкого однорідного металевого ( $\mathrm{Ag})$ покриття товщиною до 1000 нм на поверхні елементів 3 п'єзокераміки марки ЦТС-19 методом термічного осадження у вакуумі порядку (2...3)'10-3 Па.

Дослідження поверхні елементів 3 п'єзоелектричної кераміки проводилися із застосуванням атомно-силового мікроскопа «NT-206». При цьому використовувалися кремнієві зонди «Ultrasharp CSC12». Вимірювання мікрорельєфу поверхні зразків проводилося в статистичному режимі на ділянках поверхні максимальним розміром $13 \times 13$ мкм, відповідно до розроблених методик та рекомендацій.

На рис. 3 зображено топограми п'єзоелемента, отриманого традиційним шляхом в початковий момент часу $(3$, a) i через п'ять років експлуатації $(3$, б), а також отриманого нанесенням покриття у вакуумі $(3$, в) і через п'ять років експлуатації $(3$, г).

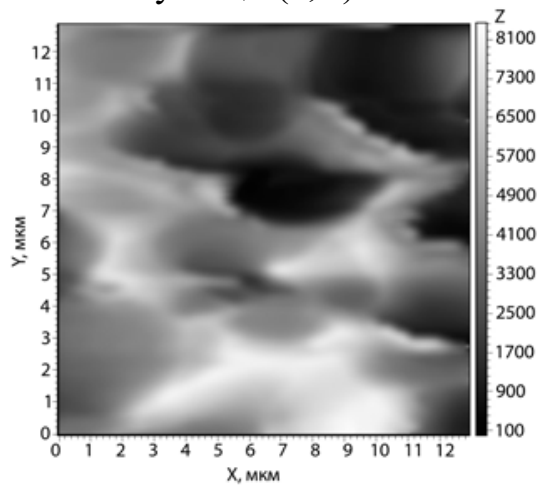

a)

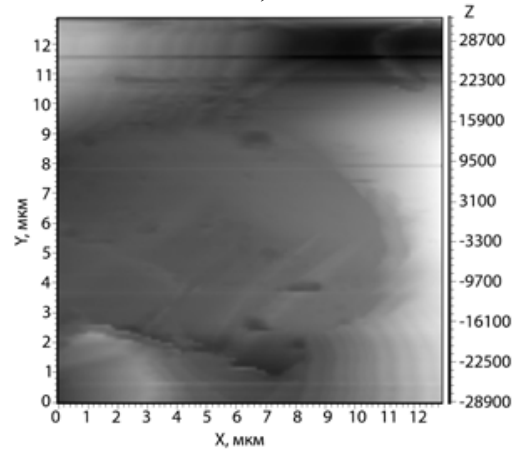

B)
Порівнюючи результати, отримані методом атомно-силової мікроскопії (ACM) до і після п'яти років експлуатації для зразків, отриманих як традиційним способом, так i методом термовакуумного напилення, можна зробити наступні висновки. Зразки, що не перебувають в експлуатації, мають значно меншу кількість артефактів сканування, на відміну від зразків, що перебувають тривалий час в експлуатації - горизонтальні лінії на топограмах (рис. 3, б, г). Такі артефакти сканування, на думку авторів, виникають у процесі контактного сканування зонду АСМ 3 досліджуваною поверхнею. На останніх, які перебувають в умовах атмосфери навколишнього середовища тривалий час, а саме, п'яти років, утворюються нестійкі з'єднання сульфідів і аміачних сполук. При скануванні такі сполуки зминаються зондом АСМ, утворюючи ці артефакти.

У той же час, проводячи порівняння зразків, отриманих традиційним способом (рис. 3, a) i методом термовакуумного напилення (рис. 3, в), можна переконатися в значному зменшенні кількості мікронерівностей і пористості поверхонь, отриманих запропонованим авторами статті методом. Останнє підтверджує перспективність цього методу при виготовленні виробів з п'єзокераміки сорту ЦТС.

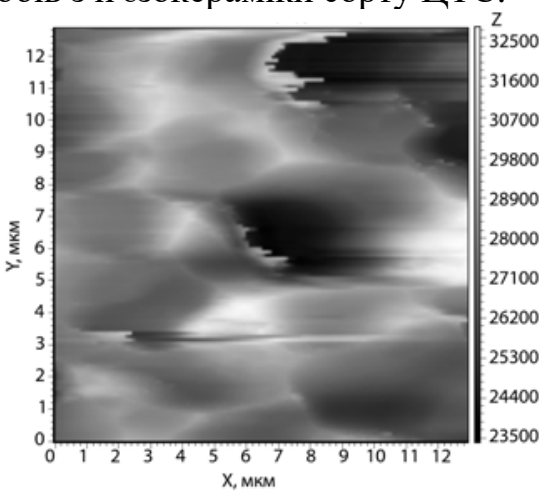

б)

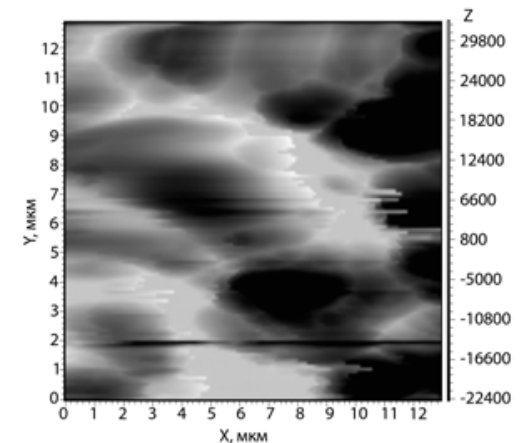

г)

Рис. 3. Топограми п'єзоелемента: отриманого традиційним шляхом у початковий момент часу (а) і через п'ять років експлуатації (б); отриманого нанесенням покриття у вакуумі (в) і через п'ять років експлуатації (г) 
На рис. 4 представлено профілі поверхні п'єзоелементів, отриманих традиційним шляхом у початковий момент часу (1) і через п'ять років експлуатації (2), а також отриманого нанесенням покриття у вакуумі (3) і че- рез п'ять років експлуатації (4). 3 отриманих профілограм видно, що експлуатація виробів, отриманих обома способами, 3 часом збільшує мікронерівності в 1,5-3,6 разу.

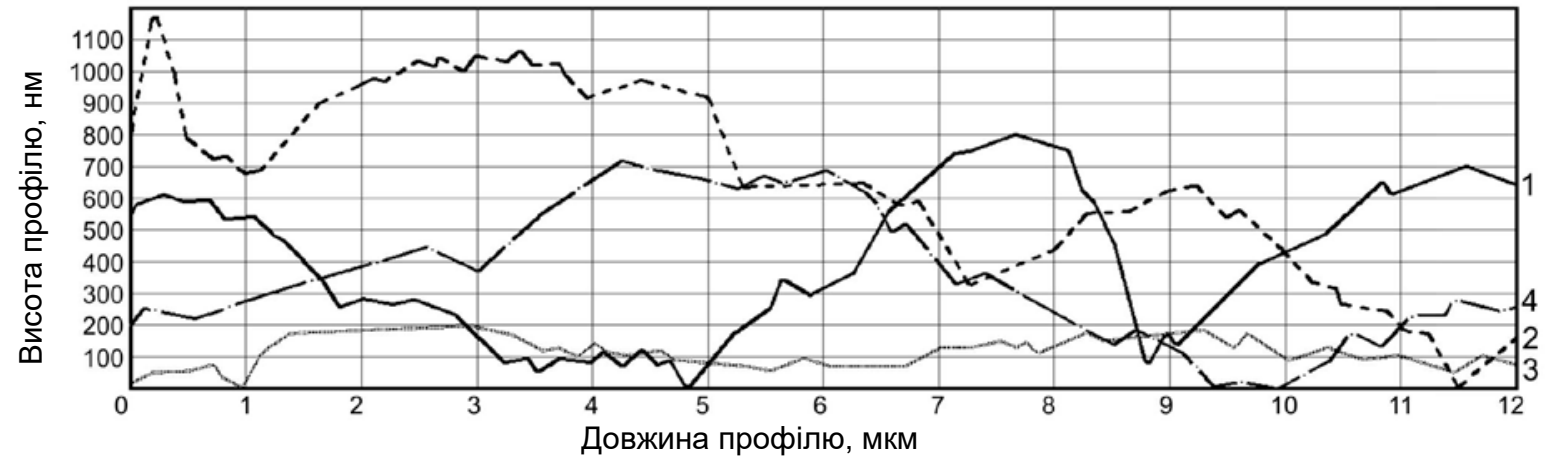

Рис. 4. Профілі поверхні п'єзоелемента: отриманого традиційним шляхом у початковий момент часу (1) і через п'ять років експлуатації (2); отриманого нанесенням покриття у вакуумі (3) і через п'ять років експлуатації (4)

На рис. 5 зображено топограми п'єзоелемента в початковий момент часу $(5$, a), через п'ять років експлуатації $(5,6)$ і через сім років експлуатації $(5$, в). 3 представлених топо- грам видно появу артефактів сканування після п'яти i, особливо, після семи років експлуатації. При цьому також відбувається збільшення пористості поверхні п'єзокераміки сорту ЦТС.

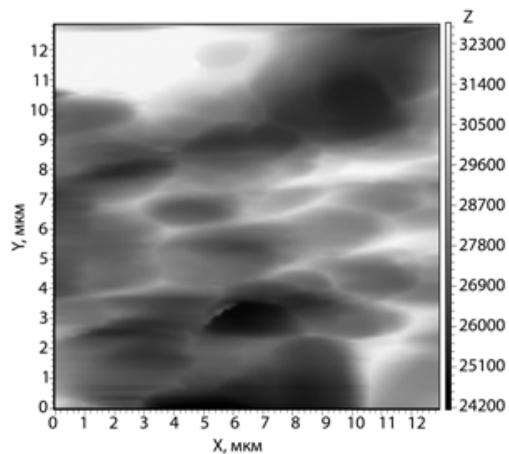

a)

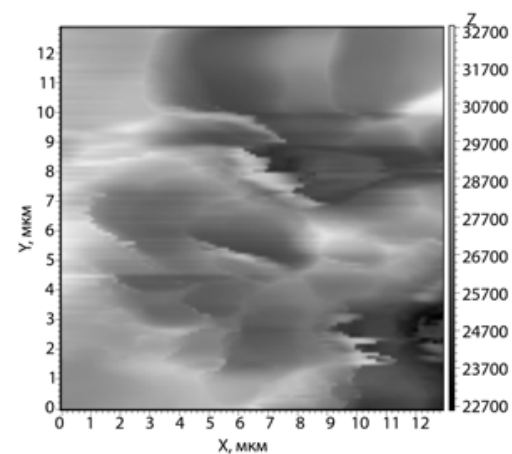

6)

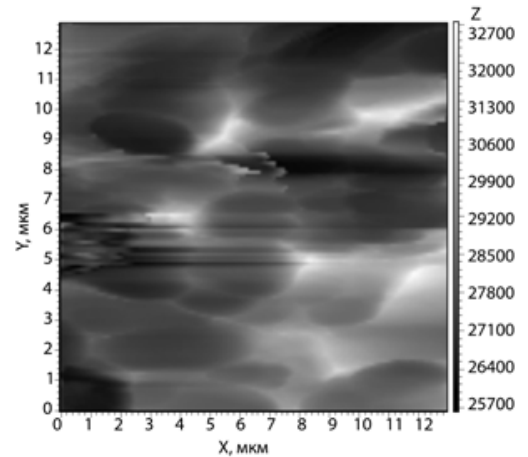

B)

Рис. 5. Топограми п'єзоелемента:

а) в початковий момент часу; б) через п'ять років експлуатації; в) через сім років експлуатації

На рис. 6 представлено профілі поверхні п'єзоелемента в початковий момент часу (1), через п'ять років експлуатації (2) і через сім років експлуатації (3).
При цьому встановлено, що мікронерівності поверхні з часом експлуатації збільшуються, відповідно, в 3,8-4,2 разу (п'ять років експлуатаціі) і 5,3-5,5 разу (сім років експлуатації).

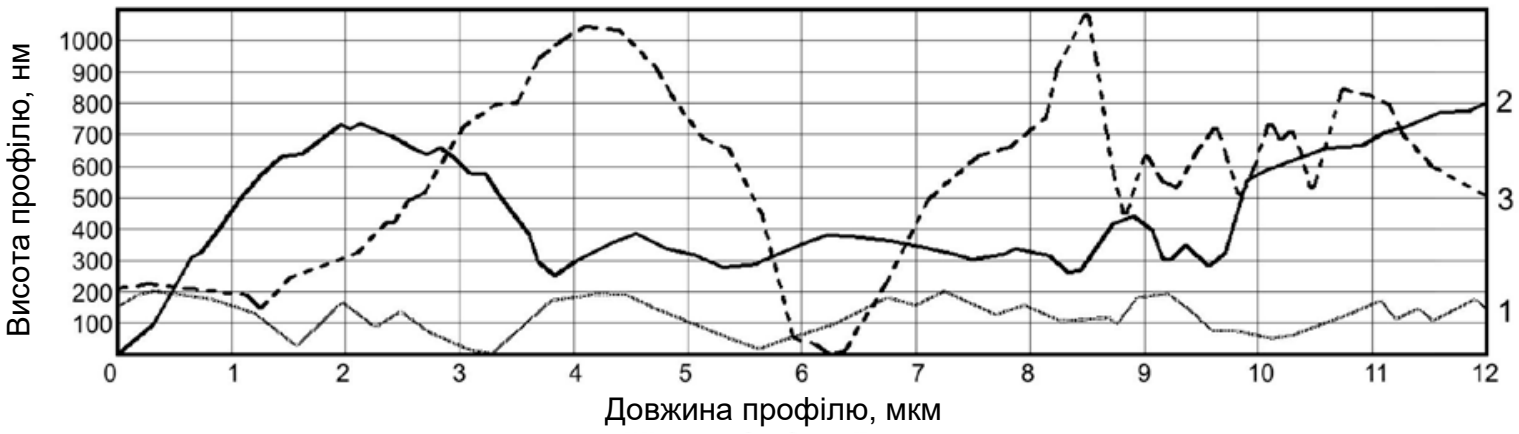

Рис. 6. Профілі поверхні п'єзоелемента:

1 - в початковий момент часу; 2 - через п'ять років експлуатації; 3 - через сім років експлуатації 
Аналіз результатів АСМ досліджень поверхонь п'єзоелектричних елементів дозволив встановити, що в процесі тривалої експлуатації відбувається руйнування їх поверхонь (рис. 4) (збільшення мікронерівностей від 805-815 нм до 1130-1180 нм (поверхні отримані традиційним методом), а також від 180-210 нм до 680710 нм (поверхні отримані методом термічного напилення у вакуумі), поява мікротріщин, відколів та інших мікродефектів).

Висновки. Для аналізу поверхні п'єзоелектричних перетворювачів використаний метод атомно-силової мікроскопії, який дозволив на початковій стадії експлуатації визначати приховані мікродефекти (мікротріщини, відколи, точки тощо) і мікронерівності, які не можуть бути визначені методами оптичної та растрової електронної мікроскопії.

Показано перспективу використання методу термовакуумного напилення при отриманні покриттів електродів на виробах 3 п'єзоелектричної кераміки сорту ЦТС.

Встановлено, що при експлуатації п'єзоелектричних перетворювачів відбувається прогресування зазначених вище дефектів (збільшення середніх значень мікронерівностей, розвиток тріщин), що призводять до передчасного виходу їх із ладу.

\section{Список літератури}

1. Varadan V., Vinoy K., Jose K. RF MEMS and their applications. 2002. John Wiley \& Sons Ltd. 406 p.

2. Бондаренко М. А., Бондаренко Ю. Ю. и др. Применение метода атомно-силовой микроскопии в прогнозировании срока эксплуатации пьезоэлектрических преобразователей медицинских приборов. Методологические аспекты сканируюшей зондовой микроскопии 2006: материалы VII Междунар. семинара. Минск, 2006. С. 143-147.

3. Петрищев О. Н. Гармонические колебания пьезокерамических элементов. Часть 1. Гармонические колебания пьезокерамических элементов в вакууме и метод резонанса - антирезонанса. Киев: Аверс, 2012. $300 \mathrm{c}$.

4. Yan Le, Wu Jian, Tang W. C. Piezoelectric micromechanical disk resonators towards UHF band. 2004. Vol. 2. P. 926-929.

5. Wang Jing, Ren Z., Nguyen C. T.-C. $1.156-\mathrm{GHz}$ self-aligned vibrating micromechanical disk resonator. IEEE Trans. Ultra- son. Ferroelectr. Freq. Control. 2004. Vol. 51. No. 12, Dec. P. 1607-1628.

6. Nguyen C. T.-C. Integrated micromechanical circuits fueled by vibrating RF MEMS technology. 2006. P. 957-966.

7. Nguyen C. MEMS technology for timing and frequency control. IEEE Trans. Ultrason. Ferroelectr. Freq. Control. 2007. Vol. 54. No. 2. P. 251-270.

8. Бондаренко М. А. и др. Формирование упорядоченных наноструктур на пьезоэлектрической керамике системы ЦТС термическим осаждением в вакууме. Эф фективность реализачии научного, ресурсного и промышленного потенциала в современных условиях: материалы Х Юбил. междунар. пром. конф. с. Славское Львовской обл., 2010. С. 159-160.

9. Шарапов В. М., Гуржий А. М., Бондаренко М. А. и др. Исследование характеристик токопроводящих электропроводных пьезокерамических элементов. Вісник Черкаського державного технологічного університету. Серія: Технічні науки. Черкаси: ЧДТУ, 2007 (спецвип.). С. 258-260.

\section{References}

1. Varadan, V., Vinoy, K., Jose, K. (2002) RF MEMS and their applications. John Wiley \& Sons Ltd, $406 \mathrm{p}$.

2. Bondarenko, M. A., Bondarenko, Yu. Yu. et al. (2006) Application of the method of atomic force microscopy in predicting the lifetime of piezoelectric transducers of medical devices. Methodological Aspects of Scanning Probe Microscopy 2006: materials of the VII Internat. seminar. Minsk, pp. 143-147 [in Russian].

3. Petrishchev, O. N. (2012) Harmonic oscillations of piezoceramic elements. Part 1. Harmonic vibrations of piezoceramic elements in vacuum and a method of resonance - antiresonance. Kyiv: Avers, 300 p. [in Russian].

4. Yan, Le, Wu, Jian, Tang, W. C. (2004) Piezoelectric micromechanical disk resonators towards UHF band, Vol. 2, pp. 926-929.

5. Wang, Jing, Ren, Z., Nguyen C. T.-C. (2004) 1.156-GHz self-aligned vibrating micromechanical disk resonator. IEEE Trans. Ultrason. Ferroelectr. Freq. Control, Vol. 51, No. 12, Dec., pp. 1607-1628.

6. Nguyen, C. T.-C. (2006) Integrated micromechanical circuits fueled by vibrating RF MEMS technology, pp. 957-966. 
7. Nguyen C. (2007) MEMS technology for timing and frequency control. IEEE Trans. Ultrason. Ferroelectr. Freq. Control, Vol. 54, No. 2, pp. 251-270.

8. Bondarenko, M. A. et al. (2010) The formation of ordered nanostructures on piezoelectric ceramics of PZT system by thermal deposition in vacuum. Efficiency of realization of scientific, resource and industrial potential under the present conditions: materials of the $\mathrm{X}$ Internat. industr. conf., pp. 159-160 [in Russian].

9. Sharapov, V. M., Gurzhij, A. M., Bondarenko, M. A. et al. (2007) The investigation of characteristics of electrically conductive piezoceramic elements. Visnyk Cherkaskogo derzhavnogo tehnologichnogo universitetu. Seria: Tehnichni nauky (special issue), pp. 258-260 [in Russian].

C. V. Bazilo, Ph.D. (Eng.), associated professor,

S. O. Bilokin, Ph.D. (Eng.),

M. O. Bondarenko, Ph.D. (Eng.), associated professor,

V. V. Medianyk

Cherkasy State Technological University

Shevchenko blvd, 460, Cherkasy, 18006, Ukraine

\section{THE STUDY OF MICROELECTROMECHANICAL PIEZOELECTRIC STRUCTURES BY THE METHOD OF ATOMIC FORCE MICROSCOPY}

Currently leading manufacturers of electronic components serially produce a rather extensive list of elements, in which various microelectromechanical structures are included, such as various accelerometers, which are produced by millions of copies, resonators and electrical signals filters implemented on their basis, transformers and other microminiature electromechanical systems. The main advantage of using of elements, made of piezoceramic materials, in measuring devices is determined by their special structure, which allows to implement in one such element fundamentally different schemes, for example, for simultaneous measurement of temperature, pressure and humidity. The purpose of the work is to investigate hidden microdefects and microroughnesses of the surfaces of piezoelectric transducers using atomic force microscopy.

Keywords: microelectromechanical structures, atomic force microscopy, surface microroughness, microdefects.

Стаття надійшла до редакиії 03.09.2018.

Рецензенти: В. В. Палагін, д.т.н., професор,

В. С. Антонюк, д.т.н., професор. 